\title{
Fission yeast WD-repeat protein Pop1 regulates genome ploidy through ubiquitin-proteasome-mediated degradation of the CDK inhibitor Rum1 and the S-phase initiator Cdc18
}

\author{
Kin-ichiro Kominami and Takashi Toda ${ }^{1}$ \\ Laboratory of Cell Regulation, Imperial Cancer Research Fund (ICRF), London WC2A 3PX, UK
}

In fission yeast, maintenance of genome ploidy is controlled by at least two mechanisms. One operates through the Cdc2/Cdc13 kinase, which also involves the CDK inhibitor Rum1, and the other through the S-phase regulator Cdc18. By screening for sterile mutants that show increased ploidy, we have identified a new gene, pop $1^{+}$, in mutants that become polyploid. The pop1 mutation shows a synthetic lethal interaction with the temperature-sensitive $c d c 2$ or $c d c 13$ mutation. In a pop1 mutant Rum1 and Cdc18 proteins become accumulated to high levels. The high ploidy phenotype in the pop1 mutant is dependent on the presence of the rum1 ${ }^{+}$gene, whereas the accumulation of Cdc18 is independent of Rum1. The predicted sequence of the Pop1 protein indicates that it belongs to a WD-repeat family with highest homology to budding yeast Cdc4, which participates in the ubiquitin-dependent pathway. Consistent with this notion, in a mutant of the 26S proteasome, higher molecular weight forms of Rum1 and Cdc18 are accumulated corresponding to polyubiquitination of these proteins. In the pop1 mutant, however, no ubiquitinated forms of these proteins are detected. Finally we show that Pop1 binds Cdc18 in vivo. We propose that Pop1 functions as a recognition factor for Rum1 and Cdc18, which are subsequently ubiquitinated and targeted to the $26 \mathrm{~S}$ proteasome for degradation.

[Key Words: Cell cycle; CDK inhibitor; initiation of S phase; polyploid; proteasome; fission yeast; ubiquitin]

Received December 5, 1996; revised version accepted April 25, 1997.

Maintenance of genome ploidy is one of the fundamental features for all organisms. Cells usually maintain a fixed ploidy when they divide and when they arrest at a specific stage of the cell cycle during differentiation. Ploidy is maintained by a faithful ordering between replication ( $S$ phase) and segregation ( $M$ phase) of the chromosomal DNA. $S$ phase always precedes $M$ phase in a single cell cycle and $S$ phase follows $M$ phase of the previous cycle. Coordination between $S$ and $M$ phase is crucial for a normal mitotic cell cycle (for review, see Nurse 1994). Disruption of the ordering between $S$ and $M$ phase is deleterious for the somatic cell cycle, although variation in ploidy is observed during development (e.g., OrrWeaver 1994).

There are several examples of circumstances that lead to polyploidization or over-replication either by chemical treatments or by mutations. For instance, in animal culture cells, the drug $\mathrm{K}-252 \mathrm{a}$ is shown to cause rerepli-

${ }^{1}$ Corresponding author.

E-MAIL toda@europa.lif.icnet.uk; FAX 44-171-269-3093. cation without intervening mitoses (Usui et al. 1991). In fly, mutations either in Dmcdc2 or in escargot lead to polyploid cells in imaginal discs and the central nervous system (Hayashi 1996). In Chinese hamster cell lines, the ts 41 mutation results in successive $S$ phases (Handeli and Weintraub 1992).

Recently it has become clear that protein turnover is a key mechanism for the regulation of protein levels in the cell. In particular, protein ubiquitination followed by the $26 \mathrm{~S}$ proteasome-dependent proteolysis has crucial roles in a wide variety of cellular processes (for review, see Deshaies 1995; Hochstrasser 1995). Ubiquitin, a highly conserved 76-residue protein, is joined covalently to the acceptor proteins via a multistep process. The reactions require a series of specific enzymes, including E1/ubiquitin-activating enzymes), E2 (ubiquitin-conjugating enzymes), and sometimes E3 (ubiquitin-ligases). The 26S proteasome is composed of a core protease known as the $20 \mathrm{~S}$ proteasome and a pair of regulatory complexes, often referred to as PA700. It is generally believed that the $26 \mathrm{~S}$ proteasome recognizes selectively polyubiquitinated proteins in an ATP-dependent manner, although there is 
one case where the substrate (ornithine decarboxylase) is not ubiquitinated. Ubiquitin-dependent protein degradation has emerged as a primary mechanism that regulates crucial aspects of the cell cycle. Cyclin B is a classical substrate for the proteasome, which is abruptly degraded in anaphase. Other cyclins such as those of budding yeast and human cyclin $\mathrm{E}$ are also shown to be degraded by ubiquitin-dependent proteolysis (Deshaies et al. 1995; Clurman et al. 1996; Won and Reed 1996). In addition, other important regulators for sister chromatid segregation in anaphase are degraded through the same proteasome pathway (Funabiki et al. 1996; Yamamoto et al. 1996).

Fission yeast usually proliferates as haploid cells with ploidy being maintained faithfully. Several conditions are known to cause diploidization or polyploidization, which can be classified into the following three types. The first type represents bypass of $M$ phase, which takes place in conditions leading to inactivation of $\mathrm{Cdc} 2 /$ Cdc13 (B-type cyclin), an archetype cyclin-dependent protein kinase (CDK). This includes complete disruption of the $c d c 13^{+}$gene, heat shock treatment of temperaturesensitive $c d c 2$ or $c d c 13$ mutants, or ectopic overexpression of rum1 $1^{+}$, which encodes a CDK inhibitor (Broek et al. 1991; Hayles et al. 1994; Moreno and Nurse 1994; Correa-Bordes and Nurse 1995). The second type comprises successive $S$ phase in the absence of $G_{1}, G_{2}$, and $M$ phases, which is driven by ectopic overexpression of $c d c 18^{+}$encoding a critical regulator for the initiation of $S$ phase (Kelly et al. 1993; Nishitani and Nurse 1995). The third type displays incomplete $M$ phase, which is caused by the cut 1 mutation defective in chromosome disjunction (Creanor and Mitchison 1990; Uzawa et al. 1990).

The cellular amount of the Rum1 protein is strictly regulated in a cell cycle-dependent manner such that it is extremely low in exponentially growing cells, whereas it is accumulated in those arresting at $G_{1}$. Thus, the fluctuation of the Rum 1 protein amount ensures the activation of the $\mathrm{Cdc} 2 / \mathrm{Cdc} 13$ kinase at the $\mathrm{G}_{2} / \mathrm{M}$ boundary and inhibition of premature entry into $M$ phase from the $\mathrm{G}_{1}$ phase (Moreno and Nurse 1994). It is, therefore, crucial to know how the level of Ruml is regulated in the cell cycle. Molecular mechanisms on regulation of the level of the Rum1 protein, however, remain to be determined, except that it is known that it is not transcriptionally regulated: The amount of rum $1^{+}$mRNA remains constant between exponentially growing cells and $\mathrm{G}_{1}$-arrested cells. This result suggests that the level of Ruml protein may be regulated through protein turnover.

It is known that the level of $c d c 18^{+}$mRNA as well as that of the protein is cell cycle-dependent, peaking at the $\mathrm{G}_{1} / \mathrm{S}$ boundary (Kelly et al. 1993; Nishitani and Nurse 1995; Muzi-Falconi et al. 1996). Cdc18, which shows amino acid sequence similarity to budding yeast Cdc6 (Zhou et al. 1989), is crucial for the initiation of S phase and regulates coupling between Start and $S$ phase and also between $S$ phase and $M$ phase. To initiate DNA replication at the correct timing, the $\mathrm{Cdc} 18$ protein level must be high at the $G_{1} / S$ boundary, whereas to restrain rereplication at other phases of the cell cycle, the synthesized protein must somehow be inactivated after $\mathrm{S}$ phase. To achieve such a cell cycle-dependent fluctuation, the Cdc18 protein would be expected to be shortlived and indeed it is shown to be (Muzi-Falconi et al. 1996). However, no molecular analysis has been addressed on the regulation of stability of the Cdc18 protein.

In the present study, we have identified the pop $1^{+}$ gene, which is important for maintenance of ploidy; mutations of this gene result in appearance of diploid or polyploid cells. We have found that the Rum 1 and Cdc18 proteins are highly accumulated in the pop 1 mutant, which accounts for increased ploidy of the pop1 mutant. The pop $1^{+}$gene encodes a member of a WD-repeat family with the F-box motif that is involved in the ubiquitindependent proteolysis (Bai et al. 1996). We will show that the Rum 1 and Cdc18 proteins are degraded through the proteasome pathway. Ruml and Cdc18 are polyubiquitinated in the proteasome mutant, but not in the pop1 mutant. Finally Pop1 forms a complex with Cdc18 in vivo. These findings show that the WD-repeat protein Pop1 is a novel regulator of the cell cycle that is required for degradation of Ruml and Cdc18 through the ubiquitin-proteasome pathway.

\section{Results}

popl mutations lead to an increased ploidy and cell size

Using flow cytometry (FACS), during the course of searching for sterile mutants because of a failure to arrest at $G_{1}$ phase upon nutrient starvation we isolated a novel type of mutant that showed increased ploidy. Wild-type cells arrest at a $1 \mathrm{C}$ content of DNA under nitrogen starvation condition, which is prerequisite for conjugation (Fig. 1A). In contrast, 14 mutants showed no $G_{1}$ peak; instead, they exhibited increased ploidy. In particular, three mutants $(364,422$, and 577) possessed a higher amount of DNA content such as $4 \mathrm{C}, 8 \mathrm{C}$, and possibly more in a discrete manner (Fig. $1 \mathrm{~B}-\mathrm{D}$, left), whereas the other 11 mutants showed $2 \mathrm{C}$ and $4 \mathrm{C}$ (data not shown). Also the forward scattering pattern that reflects cell size showed that, in proportion to the increase in DNA content, the cell size of these mutant cells was also increased (Fig. 1 A-D, right). Genetic analysis indicated that all the three mutants were recessive and allelic, designated pop1 (polyploidy).

FACS analysis in the exponentially growing pop $1 \mathrm{mu}-$ tant showed a similar pattern to that seen in nitrogenstarved condition. Examples of cell morphology of the pop1 mutant stained with DAPI are shown in Figure 1E. Not only cell length but also cell width of these mutants is clearly larger than that of wild type. In addition, a single large nucleus was apparent, suggesting that onset of mitosis rather than cytokinesis is defective in the pop1 mutant. The cell size of the pop1-364 mutant doubles on average compared with wild-type haploid 

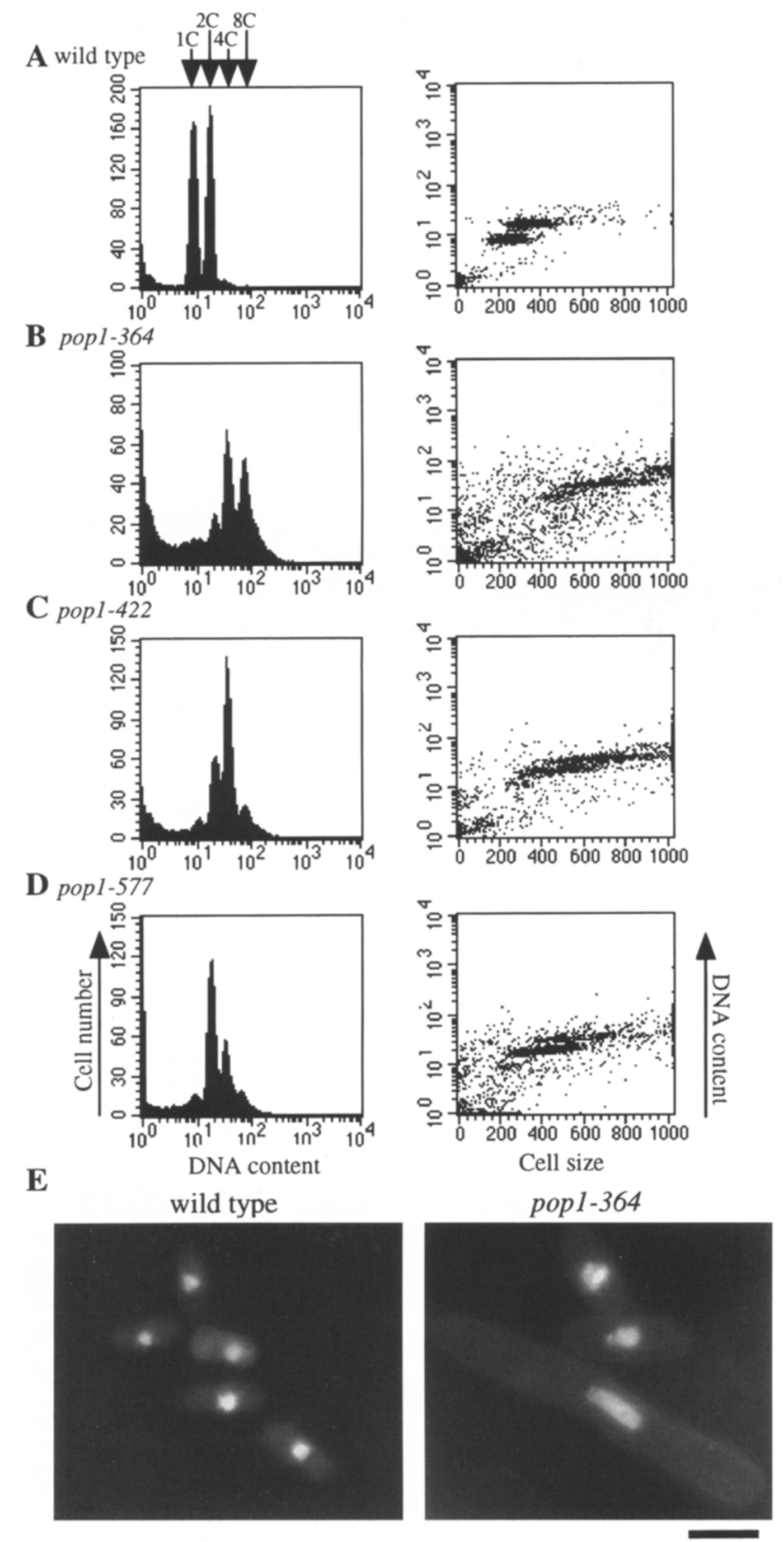

Figure 1. Phenotypes of the pop1 mutants. $(A-D)$ Cells $\mid A$, wild type, TP114-2A; $B, 364 ; C, 422 ; D, 577)$ were grown in low nitrogen medium for $24 \mathrm{hr}$ and processed for flow cytometry. (Left, $x$-axis) DNA content of individual cells in a logarithmic scale and (y-axis) frequency. (Right, $x$-axis) Forward scattering and (y-axis) DNA content. (E) Wild type (left) or pop1-364 (right) cells were grown in rich YPD medium and stained with DAPI. Bar, $10 \mu \mathrm{m}$.

cells, whereas that of diploid cells shows an $\sim 50 \%$ increase, consistent with the fact that some population of the pop1 mutant contains more than 4C DNA content (Fig. 1B). The generation time of the pop 1 mutant is $30 \%$ longer than that of wild-type cells. popl mutants are supersensitive to $K-252 a$, a drug that causes over-replication

To analyze genetically defective phenotypes of pop1, the following experiments were performed. It has been reported that a drug $\mathrm{K}-252 \mathrm{a}$ causes overreplication when added to fission yeast cells as well as animal culture cells (Usui et al. 1991, 1995). Thus, sensitivity to K-252a was examined. It was found that the pop1 mutant is supersensitive to K-252a (Table 1) but not to a related compound staurosporine (data not shown).

The popl mutations show a synthetic lethal interaction with $\mathrm{cdc} 13$ or $\mathrm{cdc} 2$

Next, synthetic phenotypes were examined between pop1 mutants and those in $c d c 2$ or $c d c 13$. The pop1 mutations $(-364,-577)$ were synthetically lethal when combined with temperature-sensitive $c d c 13-117$; dissection of 22 asci yielded no viable double mutants. We, however, sometimes obtained tiny colonies of double mutants after tetrad analysis, which were unable to propagate. Cells from these abortive colonies were extremely elongated with a single large nucleus, resembling $c d c 13$ deficient cells (Hayles et al. 1994). Conversely, multicopy plasmids containing the $c d c 13^{+}$gene were capable of suppressing partially the pop1 mutation /data not shown). These results suggest that either activity or level of the $\mathrm{Cdc} 2 / \mathrm{Cdc} 13$ kinase complexes is decreased in the pop1 mutant.

A similar synthetic phenotype was also observed between $p o p 1$ and temperature-sensitive $c d c 2-33$. A pop1 $c d c 2-33$ mutant was not lethal at low temperature $\left(26^{\circ} \mathrm{C}\right)$; however, the double mutant could not form colonies at $32^{\circ} \mathrm{C}$ at which either single mutant was capable of forming colonies. This result also supports the notion that the $\mathrm{Cdc} 2 / \mathrm{Cdc} 13$ kinase was reduced in the pop1 mutant. In contrast, the pop1 mutant did not show synthetic lethal phenotypes with the $\mathrm{G}_{1}$-arrest $c d c 10-129$ or $\mathrm{G}_{2}$-arrest cdc25-22 mutant.

The Rum1 and Cdc18 proteins are accumulated in the popl mutant

As a first step in analyzing defective phenotypes of the

Table 1. K-252a supersensitivity of the pop1 mutant

\begin{tabular}{lcccc}
\hline & \multicolumn{5}{c}{ Concentrations of K-252a $(\mathrm{\mu g} / \mathrm{ml})^{\mathrm{b}}$} \\
\cline { 2 - 5 } Strains $^{\mathrm{a}}$ & 0 & 6 & 10 & 20 \\
\hline Wild type & ++ & ++ & + & - \\
pop1-364 & ++ & + & - & - \\
spop1 & ++ & + & - & - \\
spck2 & ++ & ++ & + & -
\end{tabular}

Each strain was streaked on rich YPD plates with or without indicated concentrations of K-252a and incubated at $30^{\circ} \mathrm{C}$ for 3 days.

a pop1-364 (364); $\Delta$ pop1 (KK203); and $\Delta$ pck2 (TP170-2B).

$\mathrm{b}(++)$ Colony size was indistinguishable from that on plates without drug $;(+)$ smaller colonies were formed; $(-)$ no colonies were formed. 
pop1 mutant at a molecular level, the amount of various cell cycle regulators was examined by immunoblotting. Proteins examined include $\mathrm{Cdc} 2, \mathrm{Cdc} 13, \mathrm{Cdc} 18$, and Rum1. Total cell extracts were prepared from wild-type, the pop1 mutant, $\Delta$ rum1, and rum $1^{+}$-overproducing cells, and immunoblotting was performed using respective antibodies. As shown in Figure 2A, it was found that the level of Rum 1 protein was increased significantly in the pop1 mutant (lane 2). As reported previously (CorreaBordes and Nurse 1995), the level of Ruml protein in exponentially growing wild-type cells was extremely low and hardly detected (lane 1). In contrast, cells carrying ectopically overexpressed rum $1^{+}$gene on plasmids produced a high level of Rum 1 protein (lane 4).

In addition to the Ruml protein, the level of Cdcl 8 was also found to be accumulated in the pop 1 mutant (Fig. 2B, lane 2). In contrast to an increased level of Rum1 and $\mathrm{Cdc} 18$, the level of $\mathrm{Cdc} 13$ and $\mathrm{Cdc} 2$ was not changed

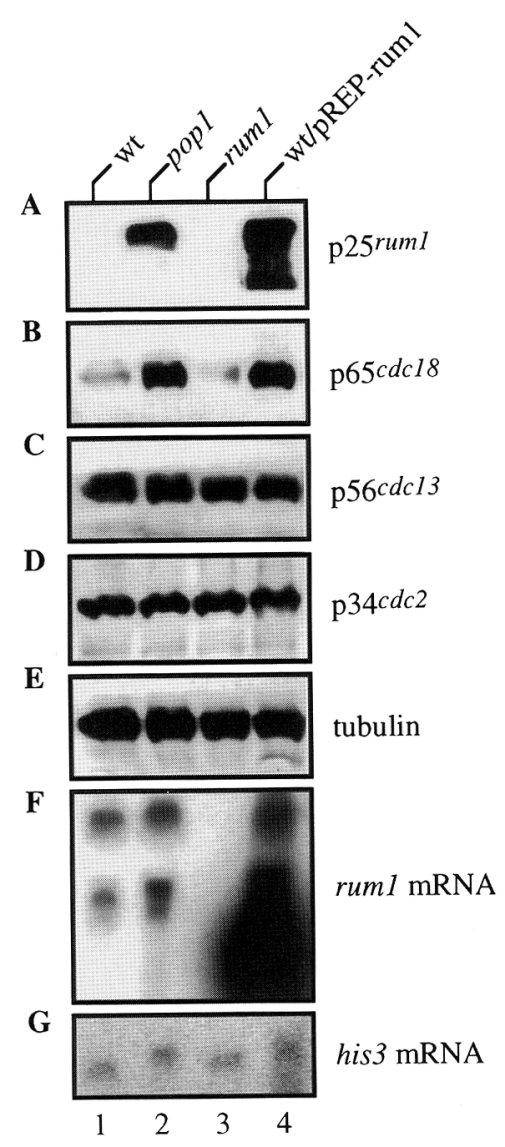

Figure 2. The Rum1 and Cdc18 proteins are accumulated in the pop1 mutant. $(A-E)$ Wild type (lane 1), the pop1 mutant (lane 2, KK203), Arum1 (lane 3), or wild type containing pREP3Xrum $1^{+}$(lane 4) was grown either in rich YPD liquid medium (lanes $1-3$ ) or in minimal medium (induced for $16 \mathrm{hr}$, lane 4). Total proteins $(25 \mu \mathrm{g})$ were run in each lane. $(F, G)$ Total RNAs were prepared from the same strains as in $A-E$. Labeled probes containing the rum $1^{+}(F)$ or his $3^{+}(G)$ genes were used for hybridization. significantly in the pop1 mutant (Fig. 2C,D; tubulin was used as a loading control in Fig. 2E).

\section{Accumulation of the Rum1 protein in the pop1 mutant is not attributable to an increased transcription}

To address the question of how the Ruml protein is accumulated in the pop1 mutant, total RNAs were prepared from the same strains as used in immunoblotting and Northern analysis was performed with the rum $1^{+}$ gene as a probe. As shown in Figure $2 \mathrm{~F}$, in a clear contrast to the protein level, the amount of the rum $1^{+}$mRNA was not increased in the pop1 mutant (cf. lanes 1 and 2), whereas a significant increase in the rum $1^{+}$RNA was detected in cells where the rum $1^{+}$gene was expressed ectopically (lane 4; note that the difference in the size of the rum $1^{+}$mRNA because of ectopic expression). These results suggest that the increase in Rum 1 protein in the pop1 mutant is not attributable to transcriptional induction of the rum $1^{+}$gene; instead, it is a result of posttranscriptional or post-translational mechanisms (see below).

The popl mutant is more susceptible to a higher dosage of the rum $1^{+}$or $\mathrm{cdc} 18^{+}$gene

If the accumulation of the Rum 1 and/or Cdc18 proteins is responsible for the increased ploidy in the pop $1 \mathrm{mu}$ tant, it is predicted that even moderate overexpression of the rum $1^{+}$or $c d c 18^{+}$gene in the pop 1 mutant would be lethal, whereas wild-type cells would be able to survive. To examine this possibility, the pop1 mutant was transformed with multicopy plasmids that contain the rum $1^{+}$ or $c d c 18^{+}$gene under the thiamine-repressible nmt1 promoter of either the strong (pREP3X) or crippled version (pREP41 and 81). We found that the pop1 mutant carrying either $\mathrm{pREP3X}$-rum $1^{+}$or pREP41-rum $1^{+}$grew extremely slowly compared with those carrying an empty vector even in repressed condition (Fig. 3A, left). In wild type, pREP3X-rum $1^{+}$, not pREP41-rum $1^{+}$, is toxic only in derepressed condition (Fig. 3A, middle). This result indicates that the pop 1 mutant becomes highly susceptible to an increase of the rum $1^{+}$gene dosage possibly because of the increase in Rum 1 protein level.

An analogous susceptibility to an increased gene dosage was also observed in the $c d c 18^{+}$gene. The pop1 mutant carrying pREP41-cdc18 $8^{+}$was capable of forming tiny colonies on plates in derepressed conditions, whereas wild-type cells carrying pREP41-cdc18+ could form colonies of size indistinguishable from those carrying a vector (Fig. $3 \mathrm{~A}$, left, and $3 \mathrm{~B}$, left and middle). Similarly, wild-type cells carrying pREP3X-cdc18 $18^{+}$managed to form tiny colonies, whereas no colonies were formed in the pop 1 mutant carrying pREP3X-cdc18+. Thus pop 1 becomes susceptible to an increased gene dosage of either rum $1^{+}$or $c d c 18^{+}$consistent with the accumulation of Rum 1 and Cdc18 in the pop1 mutant. 
A
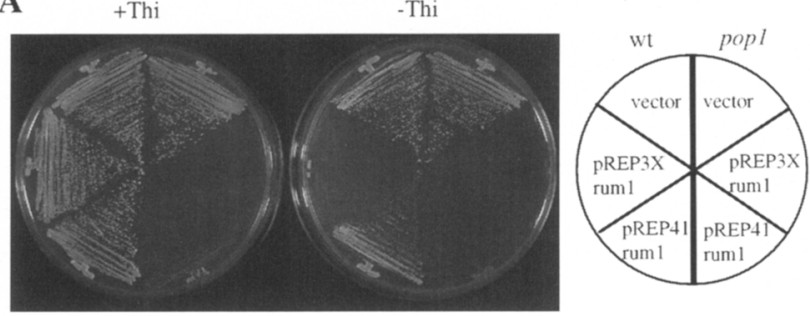

B
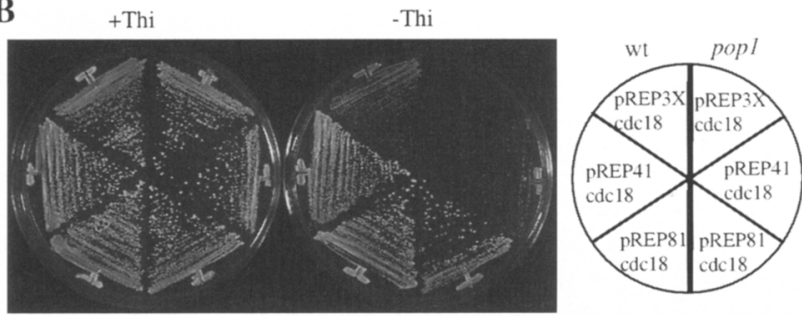

C

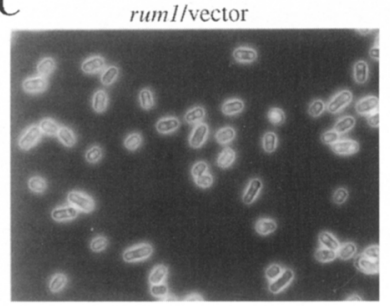

D
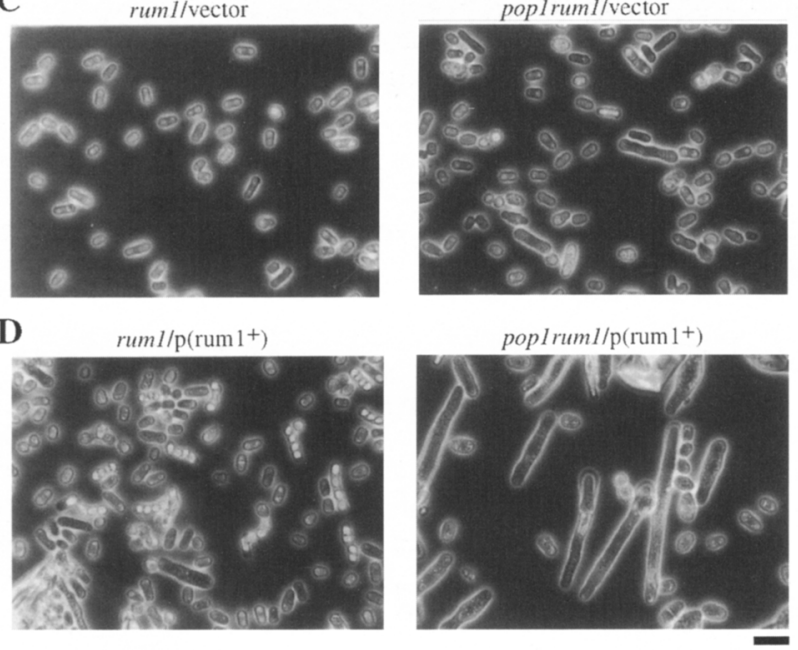

Figure 3. Genetic interaction between pop1 and rum 1 or cdc18. $(A, B)$ Wild-type or pop1 mutant (KK203) carrying a vector, pREP3X-rum $1^{+}$or pREP41-rum $1^{+}|A|$, or pREP3X-cdc18 pREP41-cdc18 ${ }^{+}$, or pREP81-cdc1 $18^{+}(B)$ was streaked on minimal plates with (left) or without (middle) thiamine. $(C, D)$ $\Delta r u m 1$ or pop1 rum 1 mutant carrying a vector $(C)$ or $\mathrm{pREP} 3 \mathrm{X}-$ rum $^{+}(D)$ was grown on minimal medium containing thiamine. Note that $\Delta r u m 1$ cells containing pREP3X-rum $1^{+}(D$, left $)$ were sporulating. Bar, $10 \mu \mathrm{m}$.

Rum 1 is required for the polyploid phenotype of the popl mutant

To examine a consequence of the loss of the rum $1^{+}$gene function in the pop 1 mutant, a double mutant between pop1 and $\Delta r u m 1$ was constructed. It was found that the polyploid phenotype caused by the pop 1 mutation was suppressed, although not completely (see below) by the rum1 deletion; cell size of the pop1 rum1 double mutant was much smaller than that of the pop1 mutant (Fig. 3C, right; see Fig. 1E for comparison). FACS analysis indicated that the double mutant contains the $2 \mathrm{C}$ content of DNA like wild type (data not shown). The double mutant is still sterile like the $\Delta$ rum 1 cells. Introduction of the rum $1^{+}$gene into this double mutant reverted to wider and elongated cell morphology, reminiscent of the pop1 mutants (Fig. 3D, right). This result demonstrates that increased ploidy in the pop 1 mutant is attributable to the accumulation of a CDK inhibitor, Ruml. It should be noted that cell size of the pop 1 rum 1 double mutant is still slightly longer than that of either wild type or Arum1 (Fig. 3C, cf. right and left panels). This phenomenon led us to pursue a relationship between Popl and Cdc18.

The Cdc18 protein accumulates in the pop1 mutant independently of the Rum1 function

It has been reported that cells carrying an increased dosage of the rum $1^{+}$gene accumulate the $\mathrm{Cdc} 18$ protein although the molecular mechanisms remain to be determined (Jallepalli and Kelly 1996; Fig. 2B, lane 4). It is, therefore, interesting to see whether the Cdc18 protein still accumulates in the pop1 rum 1 double mutant. If the accumulation of $\mathrm{Cdc} 18$ in the pop1 mutant is a secondary effect attributable to the accumulation of Rum1, the pop1 rum1 double mutant would contain a normal amount of Cdc18. If, on the other hand, the amount of the Cdc1 8 protein is regulated by Popl independently of Ruml, it would be expected that Cdc18 still accumulates in the double mutant. Immunoblotting indicated that the latter is the case. The double mutant still contained a higher amount of Cdc18, like a single pop1 mutant or cells containing ectopically expressed rum $1^{+}$gene (Fig. 4A). This result shows that the accumulation of Cdc18 in the pop1 mutant is not a secondary effect attributable to the accumulation of Ruml and that Popl regulates the amount of the Rum 1 and Cdc1 8 proteins in an independent manner.

In line with the independence of the accumulation of Rum 1 and Cdc18 in the pop 1 mutant, it was found that, like in a pop1 single mutant (Fig. 3B), pREP41-cdc1 $18^{+}$as well as pREP3X-cdc18 ${ }^{+}$is toxic in the pop1 rum 1 double mutant (Fig. 4B). Cells of the pop1 rum1 double mutant carrying pREP41-cdc18 $18^{+}$became much longer, whereas wild-type cells carrying the same plasmid did not (Fig. $4 \mathrm{Cl}$. These results support further the notion that $\mathrm{Cdc} 18$ accumulates in the pop 1 mutant in the absence of Rum 1 and that the accumulation of $\mathrm{Cdc} 18$ does contribute phenotypes of the pop1 mutant, although minor compared with that of Ruml.

\section{The predicted Pop1 protein belongs to a WD-repeat protein family}

The pop $1^{+}$gene was isolated by complementation using cdc2-33 pop1-364 double mutant as a host (see Materials and Methods). A 2325-bp uninterrupted open reading frame (ORF) that encodes a protein of 775 amino acid residues was found (Fig. 5A). A comparison of the predicted amino acid sequence between Popl and known proteins shows that the Popl protein is a member of WD-repeat proteins, which are composed of tandem repeats of the unit consisting of $\left(\mathrm{GH}-\mathrm{X}_{23-41}-\mathrm{WD}\right)^{\mathrm{N} 4-8}$ 
A

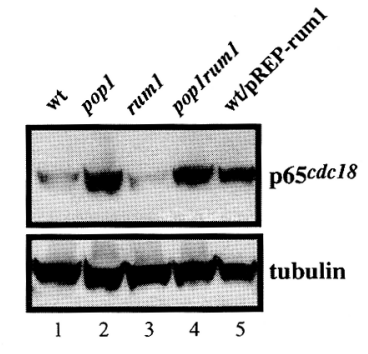

B
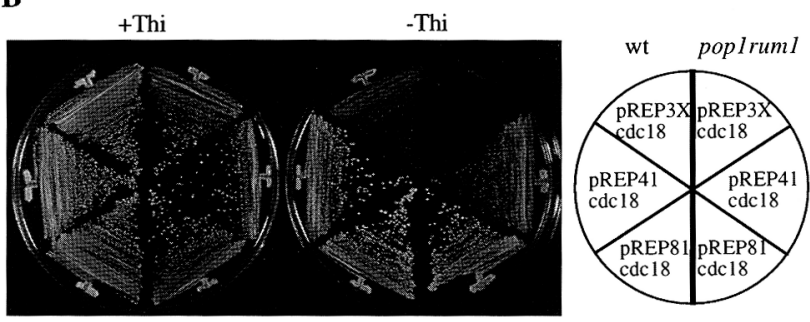

C

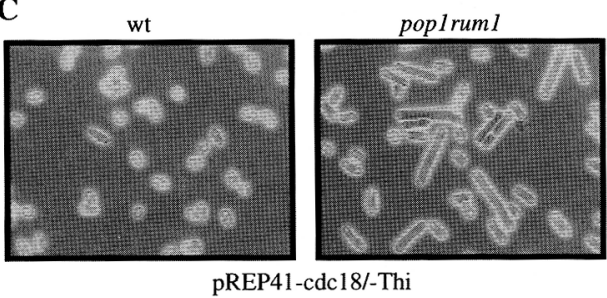

Figure 4. Stability of the Cdc18 protein in the pop 1 mutant is regulated independently of Rum1. (A) Wild type (lane 1), the pop1 mutant (KK203, lane 2), srum1 (lane 3), pop1 rum1 (lane 4,) or wild type containing pREP3X-rum $1^{+}$(lane 5) was grown as described in Fig. 2. $(B)$ Wild type or the pop1 rum 1 double mutant carrying indicated plasmids was streaked on minimal plates with (left) or without (middle) thiamine. (C) Morphology of cells carrying pREP4l-cdc18 $18^{+}$grown on minimal plates is shown. (Left) Wild type; (right) the pop1 rum1 mutant. Bar, 10 $\mu \mathrm{m}$.

(Neer et al. 1994; Fig. 5B,C). The Pop1 protein appears to contain seven repeats.

A homology search against known databases (EMBL, PIR, and SWISS-PROT) indicates that the Popl protein shows the highest homology to Cdc4 from budding yeast Saccharomyces cerevisiae (Fong et al. 1986) and its putative homolog from Candida albicans (GenBank accession no. X96763). Overall identity among these proteins is not extremely high $(30 \%$ between Popl and ScCdc4 and $35 \%$ between Popl and $\mathrm{CaCdc} 4)$. It is, however, noteworthy that not only central WD-repeat motifs but also both amino- and carboxy-terminal flanking regions show a significant homology (Fig. 5B). These flanking regions of the Pop1 protein do not show any homology to other members of WD-repeat proteins. In particular, Popl contains the F-box motif, which is reported recently to exist in various proteins including Cdc4 and implicated in ubiquitin-mediated proteolysis (Fig. 5B,C; Bai et al. 1996). Functional exchangeability between Popl and ScCdc4 has been performed, however, no positive results have been obtained $(\mathrm{K}$. Kominami and $\mathrm{T}$. Toda, unpubl.).

\section{Gene disruption of the pop $1^{+}$gene}

The pop $1^{+}$gene was disrupted by one-step gene replacement method (Fig. 5A; see Materials and Methods). The pop1-deleted ( $\Delta p o p 1)$ cells were viable and essentially the same phenotypes as the original mutants observed: increased ploidy and sterility. Thus, the pop $1^{+}$gene is not essential for viability but required for maintenance of ploidy.

\section{Identification of the pop $1^{+}$gene product}

To identify the pop $1^{+}$gene product, the pop $1^{+}$gene was fused with a tag and introduced into the pop1 mutant. Immunoblotting using anti-hemagglutinin ( $\mathrm{HA})$ antibody showed that the Pop1 protein was detected as a band of $\sim 90 \mathrm{kD}$. Approximately $40 \%$ of the Popl protein was found as an insoluble fraction (Fig. 6A, lanes 5,6). This might imply that some of the Popl protein forms a large structural complex inside the cell.

As a first step in determining the cell cycle-dependent regulation of the level of the Pop1 protein, the amount of Popl during the cell cycle was examined by arrest-release using the $\mathrm{G}_{2}$-arrest $c d c 25$ mutant. No noticeable fluctuation of the Pop1 protein in the cell cycle appeared to occur (Fig. 6B).

\section{The Rum1 and Cdc18 proteins are accumulated in the proteasome-deficient mutant}

In budding yeast Cdc4 is involved in ubiquitin-dependent proteolysis of a CDK inhibitor, Sicl (Schwob et al. 1994). Bearing this in mind, the possibility that Rum 1 and Cdc18 are degraded through the proteasome-mediated pathway was examined. To this end, the temperature-sensitive mts3-1 mutant that is defective in subunit 14 of the $26 \mathrm{~S}$ proteasome regulatory complex (Gordon et al. 1996) was used. Total cell extracts were prepared from wild type and $m t s 3-1$, which were incubated at restrictive temperature $\left(35.5^{\circ} \mathrm{C}\right)$ and were immunoblotted using anti-Ruml and anti-Cdc18 antibodies. As shown in Figure $7 \mathrm{~A}$, it was found that both Ruml and Cdc18 proteins became accumulated in the mts3-1 mutant at $35.5^{\circ} \mathrm{C}$ (lanes 5-8). It is noteworthy that even at $0 \mathrm{hr}$, the Rum1 protein could be detected in the mts3-1 mutant (lane 5). The extent of the accumulation of the Ruml protein was higher than that of the Cdc18 protein, probably because of cell cycle-dependent transcriptional regulation of the $c d c 18^{+}$gene (Nishitani and Nurse 1995; Muzi-Falconi et al. 1996). This result strongly suggests that the Ruml and Cdc1 8 proteins are degraded through the $26 \mathrm{~S}$ proteasome-dependent pathway and the Popl protein is involved in degradation of these two proteins.

\section{The Rum1 and Cdc18 proteins are polyubiquitinated} but not in the pop1 mutant

If Rum 1 and Cdc1 8 are degraded through the $26 \mathrm{~S}$ proteasome, it would be expected that these proteins become polyubiquitinated in the proteasome mutants. If so, it 
Figure 5. Cloning of the $p o p 1^{+}$gene and its predicted amino acid sequence. $(A)$ Restriction map and complementation test of the $p o p 1^{+}$gene. Arrowhead represents a subclone where the SacI site was disrupted. Restriction enzymes shown: (BgII) BgIII; $(\mathrm{H})$ HindIII; (Mlu) MluI; (ScI) SacI; (Sm) Sma. (B) Schematic drawing of the fission yeast Popl (Pop1), S. cerevisiae $\mathrm{Cdc} 4$ (ScCdc4) and C. albicans $\mathrm{Cdc} 4$ homolog (CaCdc4). Values represent percentage of identity of amino acids. Note that the third WD repeat in Pop 1 and $\mathrm{CaCdc} 4$ is shown with ovals as the number of amino acids in these repeats is larger (see Fig. $5 \mathrm{C} \mid .(\mathrm{C}) \mathrm{A}$ comparison of amino acid sequences of Pop1, ScCdc4, and $\mathrm{CaCdc} 4$. Identical amino acids are shown in closed squares; conservative amino acids are shown in gray squares. The position of the WD repeats and F-box is also shown.

would be interesting to see what happens in the pop1 mutant. To examine this possibility, a tagged version of Ruml (Ruml-HA) was overproduced in the mts3-1 or pop1 mutant and ubiquitination of Ruml was examined (see Materials and Methods). Immunoblotting with antiHA antibody against extracts prepared from $m t s 3-1$ incubated at $26^{\circ} \mathrm{C}$ (Fig. $7 \mathrm{~B}$, lane 3 ) or $35.5^{\circ} \mathrm{C}$ (lane 2) revealed that, in addition to a predicted size of Ruml-HA $(38 \mathrm{kD})$, higher molecular mass forms were detected in a discrete pattern. To show ubiquitination of Ruml-HA, the same filter was immunoblotted with anti-ubiquitin antibody. As expected, a similar, if not identical, band pattern of the higher molecular mass forms (emphasized with horizontal bars/ was detected with anti-ubiquitin antibody (lanes 5,6$)$. It should be noted that anti-ubiquitin antibody did not recognize a band of $38 \mathrm{kD}$, which is nonubiquitinated, showing specificity of anti-ubiquitin antibody. The ubiquitinated forms of Ruml-HA were more abundant in the mts3-1 mutants incubated at the restrictive temperature $\left(35.5^{\circ} \mathrm{C}\right.$, lane 5$)$ than at the permissive temperature $\left(26^{\circ} \mathrm{C}\right.$, lane 6). This result demonstrates clearly that Rum 1 is polyubiquitinated and degraded by the ubiquitin-26S proteasome pathway.

In contrast to a pattern in the mts3-1 mutant shown above, no higher molecular mass forms of Rum1-HA were detected, and, more important, no ubiquitinated bands were present in the pop1 mutant (Fig. 7B, lanes $1,4)$. Control immunoblotting with anti-Cdc2 antibody showed a similar level of the Cdc2 proteins with no higher molecular mass forms (Fig. 7B, bottom).

In addition to Ruml, similar results were obtained in Cdc18; myc-Cdc18 was polyubiquitinated in the $m t s 3-1$ mutant, but not in the pop1 mutant (Fig. 7C). These results establish the notion that Popl is required for ubiquitination and degradation of Rum 1 and Cdc18.

\section{The Pop1 protein forms a complex with $C d c 18$}

To define the biochemical function of the Pop1 protein more precisely, the possibility of physical interaction between Pop 1 and Cdc18 was examined. Cell extracts were prepared from cells that expressed HA-tagged Pop1 (Popl-HA) and myc-tagged Cdc18 (myc-Cdc18) (Fig. 8, lane 1), and immunoprecipitation was performed with anti-HA antibody in the presence or absence of competi-
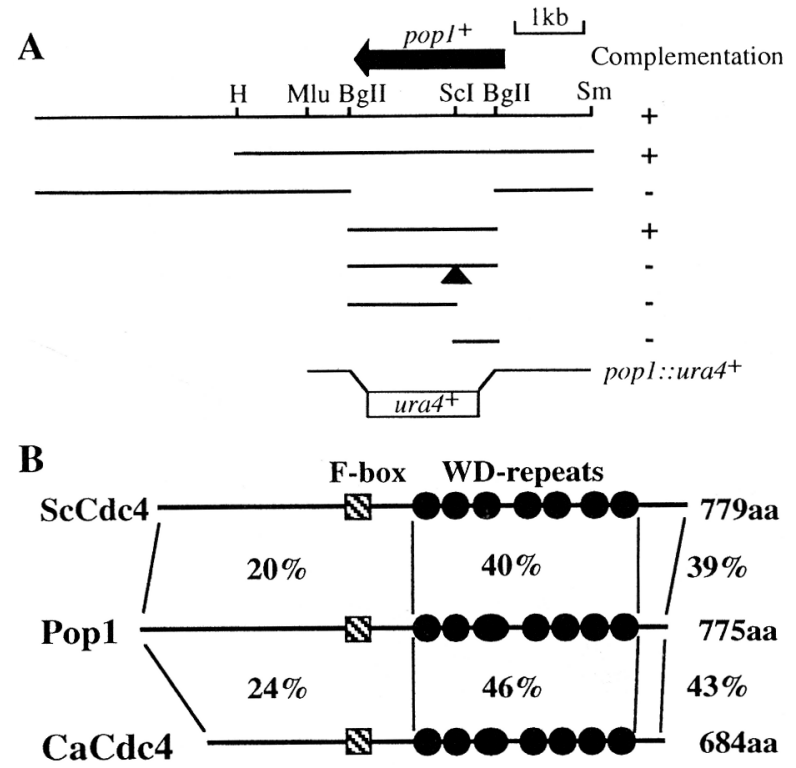

C

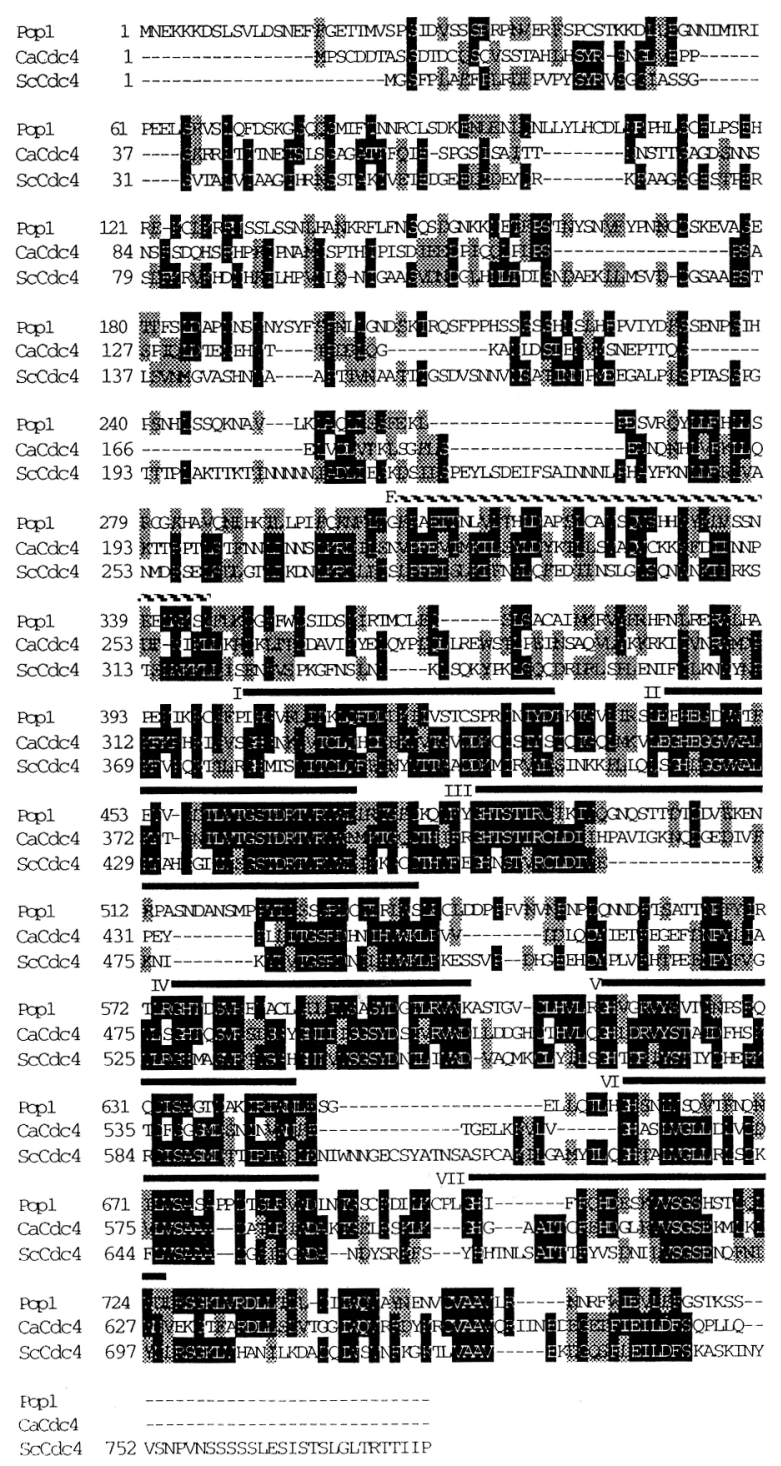


A

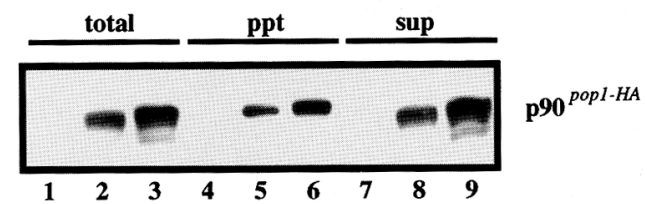

B

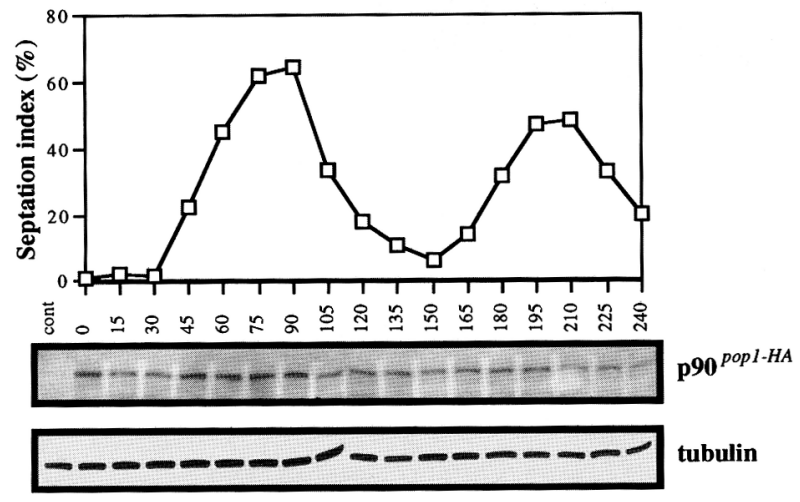

Time after shift (min)

Figure 6. Identification of the Pop 1 gene product. $\langle A|$ Cells carrying a vector (lanes $1,4,7$ ) or plasmids containing the tagged pop $1^{+}$gene (lanes $2,3,5,6,8,9$ ) were grown in minimal medium. Total extracts (lanes 1-3) were fractionated into insoluble (lanes 4-6) and soluble (lanes 7-9) fractions. (B) Exponentially growing $c d c 25$ mutant carrying the tagged pop $1^{+}$gene was first arrested at $35.5^{\circ} \mathrm{C}$ for $4 \mathrm{hr}$ and $15 \mathrm{~min}$ and shifted back to $26^{\circ} \mathrm{C}$. Aliquots were taken every $15 \mathrm{~min}$. Percentage of sepated cells is indicated to show synchrony. $c d c 25$ carrying an empty vector was shown at the left (cont).

tors. The Cdc1 8 protein, both tagged $(70 \mathrm{kD})$ and endogenous (65 kD), was coprecipitated with Pop1-HA (Fig. 8, lane 2). Neither Pop1 nor Cdc18 was precipitated when immunoprecipitation was performed in the presence of excess HA peptide (lane 3), demonstrating that the interaction between Pop1 and Cdc18 is specific. This result suggests that Pop1 functions to recognize and bind protein substrates leading to ubiquitination and degradation through the proteasome machinery.

\section{Discussion}

In this study we have identified a novel cell cycle regulator, Pop1, as a critical determinant for the maintenance of genome ploidy. In a pop1 mutant the CDK inhibitor Rum1 and the S-phase regulator Cdc18 accumulate to high level. In contrast, the pop1 rum1 double mutant no longer shows increased ploidy, suggesting that the pop 1 mutant phenotype is a result of the accumulation of the Rum 1 protein. We have shown that the Rum 1 and Cdc18 proteins are accumulated in the mutant defective in one of the subunits of the $26 \mathrm{~S}$ proteasome. Moreover, these proteins contain higher molecular mass polyubiquitinated forms with discrete band patterns. In contrast, in the pop1 mutant, no ubiquitinated forms of these proteins were detected. Finally, we have shown that Pop1 binds Cdc18 in vivo. The Pop1 protein might, therefore,

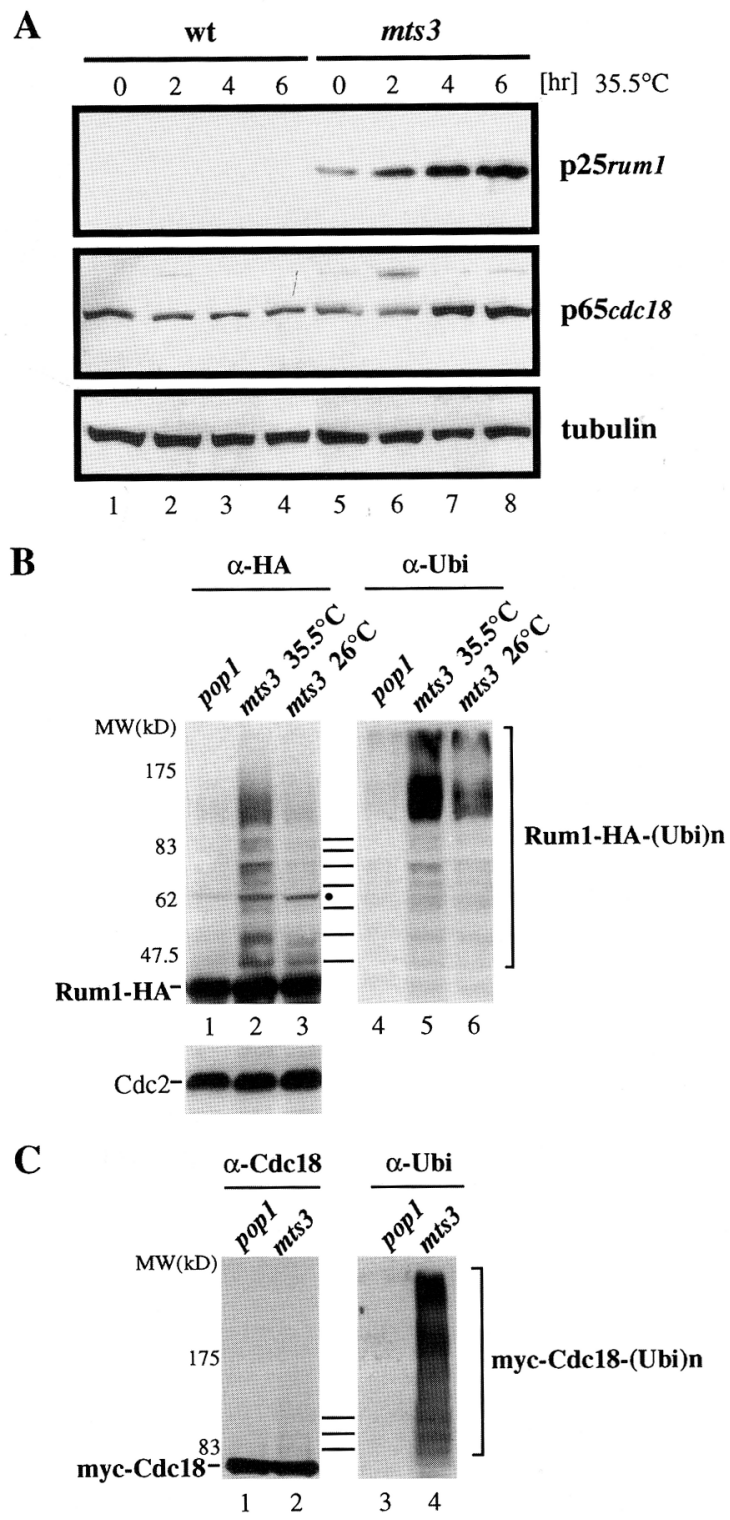

Figure 7. Degradation of Ruml and Cdc18 through the $26 \mathrm{~S}$ proteasome and ubiquitination of Rum1 and Cdc18. (A) Wild type (lanes 1-4) or mts3-1 (lanes $5-8$ ) cells grown at $26^{\circ} \mathrm{C}$ were shifted to $35.5^{\circ} \mathrm{C}$. Aliquots were taken at $0 \mathrm{hr}$ (lanes 1,5), $2 \mathrm{hr}$ (lanes 2,6), $4 \mathrm{hr}$ (lanes 3,7), $6 \mathrm{hr}$ (lanes 4,8), and immunoblotting was performed. $(B)$ Extracts were prepared (Materials and Methods) from mts3-1 (lanes 2,3,5,6) or pop1 (lanes 1,4) containing pREP41-rum $1^{+}-\mathrm{HA} / 6 \mathrm{His}$, which was grown in the absence of thiamine for $24 \mathrm{hr}$ at $26^{\circ} \mathrm{C}$ and then shifted to $35.5^{\circ} \mathrm{C}$ for $4 \mathrm{hr}$. Immunoblotting was performed either with anti-HA antibody (lanes 1-3) or with anti-ubiquitin antibody (lanes 4-6). Overlapping bands between these two blots were emphasized with horizontal lines. Note that an abundant $38-\mathrm{kD}$ nonubiquitinated form (Rum1-HA) was not detected with anti-ubiquitin antibody. (O) A band that is present in both mts3-1 and pop1. This band may be nonspecific because it is not detected with antiubiquitin antibody. $(C)$ A similar experiment as in $B$ was performed to show ubiquitination of $\mathrm{Cdcl} 8$ except that cells (mts $3-1$ at $35.5^{\circ} \mathrm{C}$ in lanes 2 and 4 , or pop 1 at $35.5^{\circ} \mathrm{C}$ in lanes 1 and 3) expressing pREP41-myc-cdc1 $8^{+}$were used. Immunoblots were performed either with anti-Cdc18 (lanes 1,2) or with anti-ubiquitin (lanes 3,4). Again, 70-kD nonubiquitinated form (myc-Cdc18) was not detected with anti-ubiquitin antibody. 


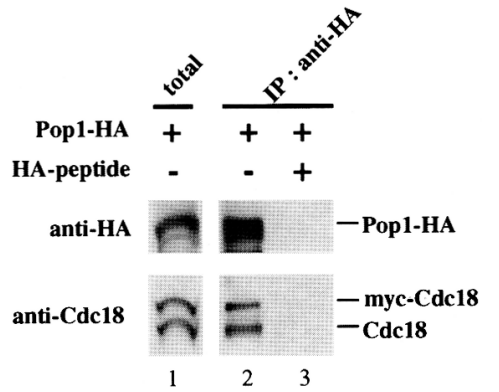

Figure 8. Physical interaction between Popl and Cdc18. Extracts were prepared from cells (PN513) that expressed pREP42pop $1^{+}-\mathrm{HA} / 6 \mathrm{His}$ and pREP41-myc-cdc18+. Immunoprecipitation was performed with anti-HA antibody in the absence (lane 2) or presence (lane 3) of HA-peptide. A pattern of immunoblots before immunoprecipitation was also shown (lane 1).

be a component or regulator of the ubiquitin-proteasome-dependent pathway that specifically recognizes a CDK inhibitor and an S-phase regulator.

\section{Identification of Pop1 as a critical regulator of ploidy control}

Despite extensive screening for diplodizing mutants, the pop1 mutants have not been identified before (Broek et al. 1991; Hayles et al. 1994). We reason that this is because of sterility and meiosis-deficiency of the pop $1 \mathrm{mu}$ tants. Previous screening was based on the assumption that diplodized mutants would undergo meiosis and form spores, which was used to enrich such increased ploidy mutants. As shown in this study, we isolated the pop1 mutants from our collections of sterile mutants using FACS. Sterility of the pop1 mutants could be attributable to inability of the pop 1 mutant to arrest at $\mathrm{G}_{1}$ upon nitrogen starvation, which is prerequisite for conjugation (Kumada et al. 1995). Failure of meiosis might be related to the accumulation of Ruml in the pop $1 \mathrm{mu}-$ tant, which would block the meiotic activation of Cdc2/ Cdc13 complexes. Alternatively, proteins other than Ruml and Cdc1 8 may become accumulated in the pop 1 mutant and might need to be degraded for meiotic progression.

The nonlethal phenotype of the pop1 disruptant is not surprising, as it has been reported that fission yeast cells can tolerate being pentaploid (Molnar and Sipiczki 1993). We have shown that Ruml protein is accumulated in the pop1 mutant, but the amount is far less than that found in lethal rum $1^{+}$-overproducing cells where the rum $1^{+}$ gene is expressed ectopically. The amount of Rum 1 protein accumulated in the pop1 mutant would be insufficient to inhibit mitoses completely. In addition, the amount of Cdc18 protein found in the pop 1 mutant appears to be insufficient to drive successive $S$ phase, as the pop1 rum1 double mutant no longer shows a high ploidy phenotype. We suspect that only some proportion of the pop1 cells bypass $M$ phase and rereplicate in each cell cycle. Alternatively, it is possible that in the pop $1 \mathrm{mu}$ - tant the overreplication occurs only in some cell cycles at a frequency that does not affect the ability to obtain colonies. Because the pop1 mutants we have isolated are not conditional, at present it is difficult to estimate precisely the frequency of rereplication per cell cycle in the mutant.

\section{Targets of Pop1-dependent proteolysis: Rum1 and Cdc18}

We suspected initially that a sole target of Pop1-dependent proteolysis might be Rum 1 as the defective phenotypes of the pop1 rum 1 double mutant are modest; FACS analysis indicated a normal ploidy $(2 \mathrm{C})$. However, subsequent analyses using the pop1 rum 1 double mutant have convinced us that the accumulation of the two proteins in the pop1 mutant is a parallel process. Pop1 regulates protein stability of Ruml and Cdc18 in an independent manner.

Regarding targets for Popl, we cannot conclude definitely that Rum 1 and $\mathrm{Cdc} 18$ are the only proteins regulated by Popl. As shown here, the high ploidy phenotypes are suppressed in the pop1 rum1 double mutants. We have found several other phenotypes of the pop $1 \mathrm{mu}$ tant in addition to increased ploidy, including a low viability in stationary phase, supersensitivity to UV exposure, and a high rate of chromosome loss. The former two phenotypes are also suppressed by the rum 1 disruption (K. Kominami and T. Toda, unpubl.), suggesting that the major targets of Pop1-dependent proteolysis are Rum1 and Cdc18.

\section{Proteasome, ubiquitin, and Pop1}

Our data show that Ruml and Cdc18 are degraded through the proteasome-dependent pathway. It is interesting to point out that, in line with this notion, mts3-1 mutant cells have been reported to rereplicate their DNA at restrictive temperature (Gordon et al. 1996). Although it was interpreted previously that overreplication is not a result of a bypass of $M$ phase, phenotypic analysis of polyploidization in the mts 3-1 mutant needs to be reexamined in view of the accumulation of Ruml and Cdc18. On the other hand, in the mts2-1 mutant, which is defective in subunit 4 of the $26 \mathrm{~S}$ proteasome (Gordon et al. 1993), neither Ruml nor Cdcl 8 is accumulated (K. Kominami and T. Toda, unpubl.). It is, therefore, possible that Rum 1 and $\mathrm{Cdc} 18$ are degraded by proteasome in a Popl-dependent and 26S subunit-specific manner.

We have shown that Popl forms a complex with Cdc18. This may suggest that a primary function of Pop1 is to recognize and bind specific substrates that are then ubiquitinated and targeted to proteasome for degradation. This is consistent with the results, which show that no ubiquitination of Rum 1 and Cdcl 8 occurs in the pop1 mutant. Pop1 may act as a tether between substrates and the E2/E3 complexes, or Pop1 may be a component of E3. Recent analysis shows that budding yeast Clns and Sic1 become phosphorylated before ubiquitination and degradation (Lanker et al. 1996; Schneider et al. 
1996; Willems et al. 1996). Cdc18 and Rum1 might need to be phosphorylated in order for Popl to recognize and bind.

Similarity to other systems: Budding yeast Cdc4, Sic1, and $C d c 6$, and human $p 27^{K i p 1}$

It is intriguing that in budding yeast $\mathrm{Cdc} 4$ is also involved in degradation of a CDK inhibitor, Sic1, through ubiquitin-mediated proteolysis. In the temperature-sensitive $c d c 4$ or $c d c 34$ mutant that is defective in ubiquitin-conjugating enzyme Ubc3 (Goebl et al. 1988), the Sic1 protein as well as Cdc6 accumulates (Schwob et al. 1994; Piatti et al. 1996). In parallel with Ruml, Sic1 becomes stabilized in $G_{1}$, which prevents premature activation of Cdc28/B-type cyclins (Clb1-6) complexes. Furthermore, like the pop1 mutant, overproduction of the B-type cyclin Clb4 is capable of suppressing partially the temperature-sensitive $c d c 4-1$ mutant (Bai et al. 1994). Although overall homology between Pop1 and Cdc4 is not extremely high $(30 \%)$, it is worth pointing out that $\mathrm{Cdc} 4$ is a protein that shows the highest homology in the entire budding yeast genome. In addition, the F-box motif that appears to be required for a physical interaction between Cdc4 and Skpl is also conserved in Pop1. Thus it is very likely that Pop1 is a fission yeast homolog of Cdc4. Skpl has been shown to be also required for ubiquitin-mediated proteolysis of $\mathrm{Cln} 2, \mathrm{Clb} 5$, and $\mathrm{Sic} 1$ (Bai et al. 1996). Cdc34 (Ubc3), Cdc53, and Skp1 are shown to act closely with Cdc4 and Sic1 (Schwob et al. 1994; Mathias et al. 1996; King et al. 1996). It is interesting to see whether in fission yeast these homologs function with Pop1 to regulate Rum1 and Cdc18.

In spite of the parallels between Popl-Rum1 and Cdc4-Sic1, defective phenotypes of the pop1 and $c d c 4$ mutants look very different. For example, the CDC4 gene is essential and mutant cells arrest in $G_{1}$ with multiple buds, whereas pop $1^{+}$is not essential and the mutant leads to overreplication. In addition, in budding yeast, mutants in subunits of the anaphase promoting complex (APC) give rise to polyploidy, implying that this complex is involved in degrading proteins that results in polyploidy when stabilized (Heichman and Roberts 1996). This phenotypic difference, however, could be explained in the following manner. Sicl inhibits Cdc28 kinase activities associated with all six B-type cyclins (Clb1-6) responsible for an S-phase progression (Donovan et al. 1994; Nugroho and Mendenhall 1994; Schwob et al. 1994). As Cln cyclins are stabilized in the $c d c 34$ mutant (Deshaies et al. 1995: Blondel and Mann 1996), the cdc4 mutant cells continue budding without DNA replication. In contrast, Rum 1 inhibits $\mathrm{Cdc} 2 / \mathrm{Cdc} 13$ and partially Cdc2/Cig2, but not Cdc2/Cig1/Correa-Bordes and Nurse 1995; Fisher and Nurse 1996; Martin-Castellanos et al. 1996). Thus even though a high level of Rum1 is present, $\mathrm{S}$ phase still occurs owing to activities of $\mathrm{Cdc} 2 /$ Cig1,2, which can compensate for loss of the S-phase function of B cyclins (Fisher and Nurse 1996; MartinCastellanos et al. 1996). A common function of Popl and $\mathrm{Cdc} 4$ can, therefore, be summarized as degradation of
CDK inhibitors Ruml and Sicl and possibly S-phase regulators $\mathrm{Cdc} 18$ and $\mathrm{Cdc} 6$. An interesting question then is whether fission yeast has CDK inhibitors other than Rum1 that inhibit Cdc2/Cigl,2 or Puc1, another $\mathrm{G}_{1}$-type cyclin (Forsburg and Nurse 1991).

A further analogy can been seen in mammalian systems where a CDK inhibitor, $\mathrm{p} 27^{\mathrm{Kip} 1}$, has been shown to be degraded through ubiquitin-dependent proteolysis (Pagano et al. 1995). Interestingly, it has been shown that Ubc3 (and Ubc2) is responsible for degradation of $\mathrm{p} 27^{\mathrm{Kipl}}$. In animal cells, CDK inhibitors that inhibit specifically Cdc2/cyclin A or B have not been identified. There is, however, circumstantial evidence that supports the existence of such CDK inhibitors (e.g., Waldman et al. 1996). In opposition to the current view of the cellular function of CDK inhibitors (Sherr and Roberts 1995), the phenotypes of the pop1 mutant leading to Ruml and Cdc18 accumulating are apparently analogous to those of tumor cells, which also result in increased ploidy, genome instability, and failure to differentiate (Hartwell and Kastan 1994). Identification of novel CDK inhibitors as well as a Pop1 homolog in mammalian cells would be a future issue to explore evolutionarily conserved functions of a WD-repeat protein.

\section{Materials and methods}

Strains, media, genetic techniques, and nomenclatures

The Schizosaccharomyces pombe strains used in this study are listed in Table 2. HM123 was used as wild type unless otherwise stated. Standard procedures for $S$. pombe genetics were followed according to Moreno et al. (1991). Low nitrogen minimal medium $\left\{0.25 \% \mathrm{NH}_{4} \mathrm{Cl}\right.$ instead of $\left.0.5 \%\right\}$ was used for nitrogen starvation experiments. Plates contained $1.6 \%$ agar. All the cultures were grown at $30^{\circ} \mathrm{C}$ unless otherwise stated. Gene disruptions are abbreviated as the gene preceded by $\Delta$, such as $\Delta p o p 1$.

\section{Isolation of the pop1 mutants}

$h^{90}$ strain (TP1 14-2A, Table 1) was mutagenized with $N$-methyl$N^{\prime}$-nitro- $N$-nitrosoguanidine. Sterile mutants (1008) were first isolated by iodine vapor treatment from $-200,000$ mutagenized colonies. Each sterile mutant was grown in low nitrogen medium for 3 days at $26^{\circ} \mathrm{C}$ and processed for FACS as described previously (Kumada et al. 1995).

\section{Allelism tests}

A cross between each mutant and wild type or a pairwise cross among mutants was performed using protoplast fusion method (Moreno et al. 1991). Crosses between the pop1 mutants (364, 422 , and 577) and wild type (HM143) showed that a mutation in the three mutants is recessive and segregates as a single chromosomal locus. In addition, all the three mutants (KK200, 422, and 577) did not complement each other, demonstrating that they were derived from mutations in the same locus.

\section{Nucleic acids preparation and manipulation}

Standard molecular biology techniques were followed as described (Sambrook et al. 1989). Enzymes were used as recommended by the suppliers (New England Biolabs Co.). For Northern analysis, $\left[\gamma^{-32}\right.$ P]ATP was used to label DNA probes (a 693-bp 
Table 2. Fission yeast strains used in this study

\begin{tabular}{|c|c|c|}
\hline Strain & Genotype & Derivations \\
\hline HM123 & $h^{-}$leu1 & our stock \\
\hline HM143 & $h^{90}$ ade6-M210 & our stock \\
\hline PN513 & $h^{-}$leu1 ura4 & P. Nurse (ICRF, London, UK) \\
\hline TP114-2A & $h^{90}$ leu 1 ura 4 & our stock \\
\hline TP170-2B & $h^{-}$leu1 pck2::LEU2 & our stock \\
\hline 364 & $h^{90}$ leu1 ura 4 pop1-364 & this study \\
\hline 422 & $h^{90}$ leu1 ura 4 pop1-422 & this study \\
\hline 577 & $h^{90}$ leu1 ura 4 pop1-577 & this study \\
\hline PN1012 & $h^{90}$ leu1 ura4 ade6 rum1::ura4 ${ }^{+}$ & P. Nurse (ICRF, London, UK) \\
\hline $\operatorname{cdc} 25$ & $h^{+} c d c 25-22$ & P. Nurse (ICRF, London, UK) \\
\hline KK199 & $h^{90}$ ura4 pop1-364 & this study \\
\hline KK200 & $h^{90}$ ade6-M210 pop1-364 & this study \\
\hline KK201 & $h^{90}$ leu1 pop1-364 cdc2-33 & this study \\
\hline KK202 & $h^{90}$ leu1 ura4 pop1-364 rum1::ura4 $4^{+}$ & this study \\
\hline CHP428/429 & $h^{-} h^{+}$leu1 leu1 ura4 ura4 his7 hid7 ade6-M210 ade6-M216 & C. Hoffman (Boston College, Chestnut Hill, MA) \\
\hline KK203 & $h^{-}$leu1 ura4 pop1::ura4 & this study \\
\hline $\mathrm{mts} 3$ & $h^{-}$leu1 mts3-1 & C. Gordon (Western General Hospital, Edinburgh, UK) \\
\hline
\end{tabular}

PCR fragment containing the rum $1^{+}$gene and a $1.2-\mathrm{kb}$ fragment containing the his $3^{+}$gene).

Construction of the rum $1^{+}$or $\mathrm{cdc} 18^{+}$gene under control of the thiamine-repressible $\mathrm{nmt} 1$ promoter

Two oligonucleotides were used to amplify the rum $1^{+}$gene by PCR: 5'-GGGCATATGGAACCTTCAACACCAC-3' and 5'GGGGGATCCTTATCGTAATAAATTGTGCC-3' where NdeI and $\mathrm{BamHI}$ sites are underlined. A 696-bp amplified fragment was subcloned into pREP41 (Basi et al. 1993), designated pREP41-rum $1^{+}$. pREP41-rum $1^{+}$is functional as it is capable of suppressing the $\Delta$ rum1 disruptant. pREP3X-rum 1+, pREP3X$c d c 18^{+}$, pREP41-cdc18 $8^{+}$, pREP41-myc-cdc18 $8^{+}$, and pREP81$c d c 18^{+}$were obtained from Dr. P. Nurse (ICRF).

\section{Cloning of the popl ${ }^{+}$gene}

The pop1-364 cdc2-33 strain (KK201) was used to isolate the pop $1^{+}$gene. Briefly the double mutant was transformed with an $S$. pombe genomic library constructed in a vector $\mathrm{pDB} 248$. $\mathrm{LEU}^{+}$ transformants that could form colonies at $32^{\circ} \mathrm{C}$ but not at $36^{\circ} \mathrm{C}$ were selected. In total 14,000 colonies were screened and three transformants were obtained. Three plasmids that contained different but overlapping insert DNAs (pKK101, 103, and 105) were obtained.

\section{Nucleotide sequence determination}

The nucleotide sequence of a 2.8-kb SmaI-BgIII fragment (Fig. $5 \mathrm{~A}$ ) was determined with the dideoxy method (Sanger et al. 1977). These sequence data are available from EMBL/GenBank/ DDBJ under accession no. Y08391.

\section{Gene disruption}

Two kinds of plasmids were constructed, an insertion and a complete deletion. For insertion, a $1.8-\mathrm{kb} \mathrm{ura}^{+}$fragment was inserted in an internal SacI site of pKK103 (Fig. 5A). For a deletion method, a 2.2 -kb $B g l I I$ fragment that encompasses $94 \%$ of ORF was deleted and replaced with a $1.8-\mathrm{kb} u r a 4^{+}$fragment. A diploid strain (CHP428/429) was used to disrupt the pop $1^{+}$gene.
Stable $\mathrm{Ura}^{+}$transformants were picked and the disruption of the pop $1^{+}$gene was verified by PCR and then tetrad analysis was performed. We obtained four viable spores where uracil auxotrophy segregates $2: 2$ and $\mathrm{Ura}^{+}$segregants showed polyploid phenotype. The pop1-364 mutant did not complement with $\Delta p o p 1$, demonstrating that the gene we cloned is pop $1^{+}$.

Construction and expression of the tagged pop $1^{+}$and ${\text {rum } 1^{+}}^{+}$ genes

The tagged version of the pop $1^{+}$gene was constructed as follows. The entire pop $1^{+}$gene was amplified by PCR using two oligonucleotides; the $5^{\prime}$ oligonucleotide is $5^{\prime}$-GGGCATATGAATGAGAAGAAAAAAGA-3' where the NdeI site is underFined and the $3^{\prime}$ oligonucleotide is 5'-GGGGCGGCCGCTAGAAGATTTAGTAGATCCAA-3' where the NotI site is underlined. A PCR-amplified 2342-bp fragment was subcloned into pREP41 (HA-6His) (provided by Dr. J. Millar, National Institute for Medical Research, London, UK) to yield pREP41pop $1^{+}-\mathrm{HA} / 6 \mathrm{His}$, which expresses the gene under the control of a partially crippled version of the $n m t 1$ thiamine-repressible promoter (Basi et al. 1993) and contains six His and two repeats of a peptide derived from the influenza HA. pREP42-pop $1^{+}-\mathrm{HA} /$ $6 \mathrm{His}$ was made by subcloning a $2.4-\mathrm{kb}$ NdeI-BamHI fragment from pREP41-pop $1^{+}-\mathrm{HA} / 6 \mathrm{His}$ into pREP42. Tagging of 6His$\mathrm{HA}$ in the carboxyl terminus did not interfere with the normal function of the Popl protein as pREP41-pop 1+-HA/6His suppressed the pop1 mutation. A 2279-bp Bg/II-BamHI fragment containing $\mathrm{HA} / 6 \mathrm{His}$ was replaced with a $2.2-\mathrm{kb} B g / \mathrm{II}$ fragment of pKK103, where the pop $1^{+}-\mathrm{HA} / 6 \mathrm{His}$ was regulated under a natural promoter. The tagged version of the rum $1^{+}$gene (pREP41-rum 1 $1^{+}-\mathrm{HA} / 6 \mathrm{His}$ ) was constructed in a manner similar to pop $1^{+}-\mathrm{HA} / 6 \mathrm{His}$ except that the following primers were used: $5^{\prime}$-GGGCATATGGAACCTTCAACACCAC-3' and 5'-GGGGGGGGGCGGCCGCTTCGTAATAAATTGTGCCTGT-3'.

\section{Immunochemical assays}

Antibodies used in this study were following; anti-Cdc2, anti$\mathrm{Cdc} 13$ (provided by Dr. H. Yamano, ICRF), anti-Rum1 (affinitypurified, a gift from Dr. J. Correa-Bordes, ICRF), anti-Cdc18 (af- 
finity-purified, a gift from Dr. H. Nishitani, ICRF), anti-tubulin antibody (T-5168, Sigma), anti-HA (16B12, BAbCO), anti-myc (9E10, ICRF), and anti-ubiquitin monoclonal antibody (MAB1510, Chemicon Inc.). Fission yeast cell extracts were prepared as described (Moreno et al. 1991). To detect the Ruml protein in total cell extracts, cells were boiled for $5 \mathrm{~min}$ before breakage with glass beads (Correa-Bordes and Nurse 1995). To detect ubiquitination of Rum1 and Cdc18, cell extracts were prepared as follows essentially according to Watanabe et al. (1997). Cells were rapidly killed by addition of the ice-cold extraction buffer $150 \mathrm{~mm}$ Tris- $\mathrm{HCl}$ at $\mathrm{pH} 7.4,1 \mathrm{~mm}$ EDTA, $10 \mathrm{~mm}$ $\beta$-mercaptoethanol, $0.5 \mathrm{~mm}$ PMSF) containing $10 \%$ of trichloroacetic acid (TCA) and disrupted with glass beads. After washing with acetone five times, the proteins were solubilized by boiling $(3 \mathrm{~min})$ in the extraction buffer containing 1\% SDS and $0.1 \mu \mathrm{M}$ ubiquitin aldehyde (kindly provided by Dr. Keiji Tanaka, The Tokyo Metropolitan Institute of Medical Science, Japan) to prevent deubiquitination. The supernatant was mixed with an equal amount of the HB buffer (Moreno et al. 1991). Standard procedures for immunoblotting were followed (Harlow and Lane 1988) except that CAPS (3-cyclohexylamino-1-propanesulfonic acid) buffer was used to detect proteins $<50 \overline{\mathrm{kD}}$ (Matsudaira 1987). For immunoprecipitation, cell extracts (2.5 mg) were mixed with anti-myc antibody or anti-HA antibody, followed by protein G-Sepharose beads (Pharmacia). HA-peptide $(40 \mu \mathrm{g})$ was added to extracts in a competitor experiment. Antiubiquitin antibody was used in 1:2500 dilution. Horseradish peroxidase-conjugated goat anti-rabbit IgG or goat anti-mouse IgG (Bio-Rad) and a chemiluminescence system (ECL, Amersham) were used to detect bound antibody.

\section{Acknowledgments}

We thank Drs. J. Correa-Bordes, C. Gordon, C. Hoffman, J. Millar, H. Nishitani, P. Nurse, and H. Yamano for the gifts of strains, plasmids, and antibodies and H. Nakano for K-252a. Special thanks are given to J. Correa-Bordes and Y. Watanabe, who instructed preparation of cell extracts and immunoblotting; to B. Baum, who kindly performed Northern blotting; and to $\mathrm{K}$. Tanaka, who generously gave us anti-ubiquitin antibody and ubiquitin aldehyde. We are grateful to D. Hirata, who first suggested the cloning of the pop $1^{+}$gene with complementation using the pop1 cdc2-33 double mutant as a host; K. Nasmyth, for stimulative discussion and comments on the manuscript; and S. Moreno, for communicating results prior to publication. We thank P. Nurse and J.F.X. Diffley for useful comments and critical reading of the manuscript. This work was in part supported by Kyowa Hakko Co.

The publication costs of this article were defrayed in part by payment of page charges. This article must therefore be hereby marked "advertisement" in accordance with 18 USC section 1734 solely to indicate this fact.

\section{References}

Bai, C., R. Richman, and S.J. Elledge. 1994. Human cyclin F. $E M B O$ J. 13: 6087-6098.

Bai, C., P. Sen, K. Hofmann, L. Ma, M. Goebl, J.W. Harper, and S.J. Elledge. 1996. SKP1 connects cell cycle regulators to the ubiquitin proteolysis machinery through a novel motif, the F-box. Cell 86: 263-274.

Basi, G., E. Schmid, and K. Maundrell. 1993. TATA box mutations in the Schizosaccharomyces pombe nmt1 promoter affect transcriptional efficiency but not the transcription start point or thiamine repressibility. Gene 123: 131-136.

Blondel, M. and C. Mann. 1996. G2 cyclins are required for the degradation of G1 cyclins in yeast. Nature 384: 279-282.
Broek, D., R. Bartlett, K. Crawford, and P. Nurse. 1991. Involvement of $\mathrm{p} 34^{c d c 2}$ in establishing the dependency of $S$ phase on mitosis. Nature 349: 388-393.

Clurman, B.E., R.J. Sheaff, K. Thress, M. Groudine, and J.M. Roberts. 1996. Turnover of cyclin E by the ubiquitin-proteasome pathway is regulated by cdk2 binding and cyclin phosphorylation. Genes \& Dev. 10: 1979-1990.

Correa-Bordes, J. and P. Nurse. 1995. p2 $5^{\text {rum } 1}$ orders S phase and mitosis by acting as an inhibitor of the $\mathrm{p} 34^{\text {cdc2 }}$ mitotic kinase. Cell 83: 1001-1009.

Creanor, J. and J.M. Mitchison. 1990. Conditional DNA synthesis after a mitotic block in the double mutant cut1 cdc11 of the fission yeast Schizosaccharomyces pombe. I. Cell Sci. 96: 433-436.

Deshaies, R.J. 1995. Make it or break it: The role of ubiquitindependent proteolysis in cellular regulation. Trends Cell Biol. 5: 428-434.

Deshaies, R.J., V. Chau, and M. Kirschner. 1995. Ubiquitination of the $\mathrm{G}_{1}$ cyclin $\mathrm{Cln} 2 \mathrm{p}$ by a $\mathrm{Cdc} 34 \mathrm{p}$-dependent pathway. EMBO I. 14: 303-312.

Donovan, J.D., J.H. Toyn, A.L. Johnson, and L.H. Johnston. 1994. p40 $40^{S D B 25}$, a putative CDK inhibitor, has a role in the $\mathrm{M} / \mathrm{G}_{1}$ transition in Saccharomyces cerevisiae. Genes \& Dev. 8: 1640-1653.

Fisher, D. and P. Nurse. 1996. A single fission yeast mitotic cyclin B p34 ${ }^{\text {cdc2 }}$ kinase promotes both S-phase and mitosis in the absence of $\mathrm{G}_{1}$ cyclins. EMBO J. 15: 850-860.

Fong, H.K., J.B. Hurley, R.S. Hopkins, R. Miyake-Lye, M.S. Johnson, R.F. Doolitle, and M.I. Simon. 1986. Repetitive segmental structure of the transducin $\beta$ subunit: Homology with the CDC4 gene and identification of related mRNAs. Proc. Natl. Acad. Sci. 83: 2162-2166.

Forsburg, S.A. and P. Nurse. 1991. Identification of a G1 type cyclin puc1 in the fission yeast Schizosaccharomyces pombe. Nature 351: 245-247.

Funabiki, H., H. Yamano, K. Kumada, K. Nagao, T. Hunt, and M. Yanagida. 1996. Cut2 proteolysis required for sister-chromatid separation in fission yeast. Nature 381: 438-441.

Goebl, M.G., J. Yochem, S. Jentsch, J.P. McGrath, A. Varshavsky, and B. Byers 1988. The yeast cell cycle gene CDC34 encodes a ubiquitin-conjugating enzyme. Science 241: 13311335.

Gordon, C., G. McGurk, P. Dillon, C. Rosen, and N.D. Hastie 1993. Defective mitosis due to a mutation in the gene for a fission yeast 26S protease subunit. Nature 366: 355-357.

Gordon, C., G. McGurk, M. Wallace, and N.D. Hastie. 1996. A conditional lethal mutant in the fission yeast $26 \mathrm{~S}$ protease subunit $m t s 3^{+}$is defective in metaphase to anaphase transition. J. Biol. Chem. 271: 5704-5711.

Handeli, S. and H. Weintraub. 1992. The ts41 mutation in Chinese hamster cells leads to successive $S$ phases in the absence of intervening G2, M, and G1. Cell 71: 599-611.

Harlow, E. and D. Lane. 1988. Antibodies: A laboratory manual. Cold Spring Harbor Laboratory, Cold Spring Harbor, NY.

Hartwell, L.H. and M.B. Kastan. 1994. Cell cycle control and cancer. Science 266: 1821-1828.

Hayashi, S. 1996. A Cdc2 dependent checkpoint maintains diploidy in Drosophila. Development 122: 1051-1058.

Hayles, J., D. Fisher, A. Woollard, and P. Nurse. 1994. Temporal order of $S$ phase and mitosis in fission yeast is determined by the state of the p34 ${ }^{\text {cdc2 }}$-mitotic B cyclin complex. Cell 78: 813-822.

Heichman, K.A. and J.M. Roberts. 1996. The yeast CDC16 and CDC27 genes restrict DNA replication to once per cell cycle. Cell 85: 39-48. 
Hochstrasser, M. 1995. Ubiquitin, proteasomes, and the regulation of intracellular protein degradation. Curr. Biol. 7:215223.

Jallepalli, P.V. and T.J. Kelly. 1996. Ruml and Cdc18 link inhibition of cyclin-dependent kinase to the initiation of DNA replication in Schizosaccharomyces pombe. Genes \& Dev. 10: 541-552.

Kelly, T.J., G.S. Martin, S.L. Forsburg, R.J. Stephen, A. Russo, and P. Nurse. 1993. The fission yeast $c d c 18^{+}$gene product couples $S$ phase to START and mitosis. Cell 74: $371-382$.

King, R.W., R.J. Deshaies, J.-M. Peters, and M.W. Kirschner. 1996. How proteolysis drives the cell cycle? Science 274: 1652-1659.

Kumada, K., S. Su, M. Yanagida, and T. Toda. 1995. Fission yeast TPR-family protein nuc2 is required for $\mathrm{G}_{1}$-arrest upon nitrogen starvation and is an inhibitor of septum formation. I. Cell Sci. 108: 895-905.

Lanker, S., M.H. Valdivieso, and C. Wittenberg. 1996. Rapid degradation of the $\mathrm{G}_{1}$ cyclin Cln 2 induced by CDK-dependent phosphorylation. Science 271: 1597-1601.

Martin-Castellanos, C., K. Labib, and S. Moreno. 1996. B-type cyclins regulates $G_{1}$ progression in fission yeast in opposition to the p2 $5^{\text {rum } 1}$ cdk inhibitor. EMBO J. 15: 839-849.

Mathias, N., S.L. Johnson, M. Winey, A.E.M. Adams, L. Goetsch, J.R. Pringle, B. Byers, and M.G. Goebl. 1996. Cdc53p acts in concert with Cdc4p and Cdc $34 p$ to control the $\mathrm{G}_{1}$-to-S-phase transition and indentifies a conserved family of proteins. Mol. Cell. Biol. 16: 6634-6643.

Matsudaira, P. 1987. Sequence from picomole quantities of proteins electroblotted onto polyvinylidene difluoride membranes. I. Biol. Chem. 262: 10035-10038.

Molnar, M. and M. Sipiczki. 1993. Polyploidy in the haplontic yeast Schizosaccharomyces pombe: Construction and analysis of strains. Curr. Genet. 24: 45-52.

Moreno, S. and P. Nurse. 1994. Regulation of progression through the $\mathrm{G} 1$ phase of the cell cycle by the rum $1^{+}$gene. Nature 367: 236-242.

Moreno, S., A. Klar, and P. Nurse. 1991. Molecular genetic analyses of fission yeast Schizosaccharomyces pombe. Methods Enzymol. 194: 773-782.

Muzi-Falconi, M., G.W. Brown, and T.J. Kelly. 1996. $c d c 18^{+}$ regulates initiation of DNA replication in Schizosaccharomyces pombe. Proc. Natl. Acad. Sci. 93: 1666-1670.

Neer, E.J., C.J. Schmidt, R. Nambudripad, and T.F. Smith. 1994. The ancient regulatory-protein family of WD-repeat proteins. Nature 371: 297-300.

Nishitani, H. and P. Nurse. 1995. p65 ${ }^{\text {cdc18 }}$ plays a major role controlling the initiation of DNA replication in fission yeast. Cell 83: 397-405.

Nugroho, T.T. and M.D. Mendenhall. 1994. An inhibitor of yeast cyclin-dependent protein kinase plays an important role in ensuring the genomic integrity of daughter cells. Mol. Cell. Biol. 14: 3320-3328.

Nurse, P. 1994. Ordering S phase and M phase in the cell cycle. Cell 73: 547-550.

Orr-Weaver, T.L. 1994. Developmental modification of the Drosophila cell cycle. Trends Genet. 10: 321-327.

Pagano, M., S.W. Tam, A.M. Theodoras, P. Beer-Romero, G.D. Sal, V. Chau, P. Renée, G.F. Draetta, and M. Rolfe. 1995. Role of the ubiquitin-proteasome pathway in regulating abundance of the cyclin-dependent kinase inhibitor p27. Science 269: 682-685.

Piatti, S., T. Böhm, J.H. Cocker, J.F.X. Diffley, and K. Nasmyth. 1996. Activation of S-phase-promoting CDKs in late G1 defines a "point of no return" after which Cdc6 synthesis cannot promote DNA replication in yeast. Genes \& Dev.
10: 1516-1531.

Sambrook, I., E.F. Fritsch, and T. Maniatis. 1989. Molecular cloning: A laboratory manual. Cold Spring Harbor Laboratory Press, Cold Spring Harbor, NY.

Sanger, F., S. Nicklen, and A.R. Coulson. 1977. DNA sequencing with chain-terminating inhibitors. Proc. Natl. Acad. Sci. 74: 5463-5467.

Schneider, B.L., Q.-H. Yang, and A.B. Futcher. 1996. Linkage of replication to Start by the cdk inhibitor Sicl. Science 272: 560-562.

Schwob, E., T. Böhm, M.D. Mendenhall, and K. Nasmyth. 1994. The B-type cyclin kinase inhibitor $\mathrm{p} 40^{S I C 1}$ controls the $\mathrm{Gl}$ to $\mathrm{S}$ transition in S. cerevisiae. Cell 79: 233-244. [Erratum 84 1996.]

Sherr, C.J. and J.M. Roberts. 1995. Inhibitors of mammalian $G_{1}$ cyclin-dependent kinases. Genes \& Dev. 9: 1149-1163.

Usui, T., M. Yoshida, K. Abe, H. Osada, K. Isono, and T. Beppu. 1991. Uncoupled cell cycle without mitosis induced by a protein kinase, K-252a. J. Cell Biol. 115: 1275-1282.

Usui, T., M. Yoshida, A. Honda, T. Beppu, and S. Horinouchi. 1995. A K-252a-related gene, $s k s 1^{+}$, encodes a protein similar to the Caenorhabitis elegans F37A4.5 gene product and confers multidrug resistance in Schizosaccharomyces pombe. Gene 161: 93-96.

Uzawa, S., I. Samejima, T. Hirano, K. Tanaka, and M. Yanagida. 1990. The fission yeast $c u t 1^{+}$gene regulates spindle pole body duplication and has homology to the budding yeast ESP1. Cell 62: 913-925.

Waldman, T., C. Lengauer, K.W. Kinzler, and B. Vogelstein. 1996. Uncoupling of $S$ phase and mitosis induced by anticancer agents in cells lacking p21. Nature 381: 713-716.

Watanabe, Y., S. Shinozaki-Yabana, Y. Chikashige, Y. Hiraoka, and M. Yamamoto 1997. Phosphorylation of RNA-binding protein controls cell cycle switch from mitotic to meiotic in fission yeast. Nature 386: 187-190.

Willems, A.R., S. Lanker, E.E. Patton, K.L. Craig, T.F. Nason, R. Kobayashi, C. Wittenberg, and M. Tyers. 1996. Cdc53 targets phosphorylated G1 cyclins for degradation by the ubiquitin proteolytic pathway. Cell 86: 453-463.

Won, K.-A. and S.I. Reed. 1996. Activation of cyclin E/CDK2 is coupled to site-specific autophosphorylation and ubiquitindependent degradation of cyclin E. EMBO \%. 15: 4182-4193.

Yamamoto, A., V. Guacci, and D. Koshland. 1996. Pdslp is required for faithful execution of anaphase in the yeast, Saccharomyces cerevisiae. J. Cell Biol. 133: 85-97.

Zhou, C., S.H. Huang, and A.Y. Jong. 1989. Molecular cloning of Saccharomyces cerevisiae CDC6 gene. J. Biol. Chem. 264: 9022-9029. 


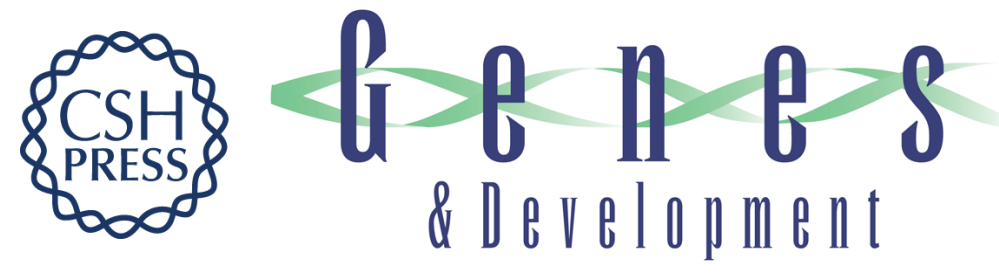

\section{Fission yeast WD-repeat protein pop1 regulates genome ploidy through ubiquitin-proteasome-mediated degradation of the CDK inhibitor Rum1 and the S-phase initiator Cdc18.}

K Kominami and T Toda

Genes Dev. 1997, 11:

Access the most recent version at doi:10.1101/gad.11.12.1548

References This article cites 56 articles, 22 of which can be accessed free at:

http://genesdev.cshlp.org/content/11/12/1548.full.html\#ref-list-1

License

Email Alerting Service

Receive free email alerts when new articles cite this article - sign up in the box at the top right corner of the article or click here.

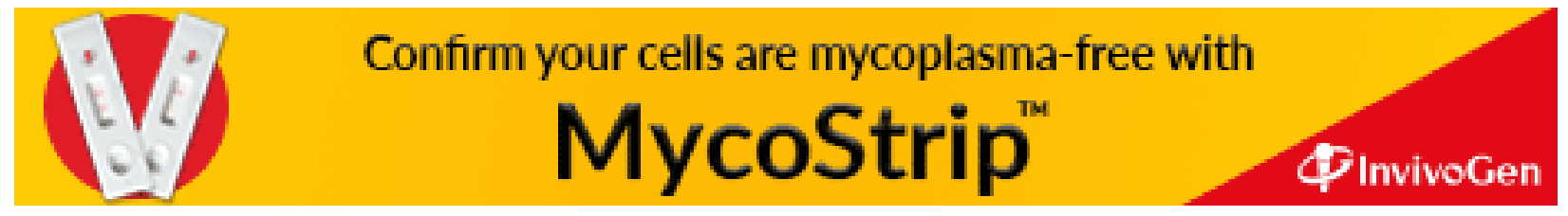

